Thessaly, Greece

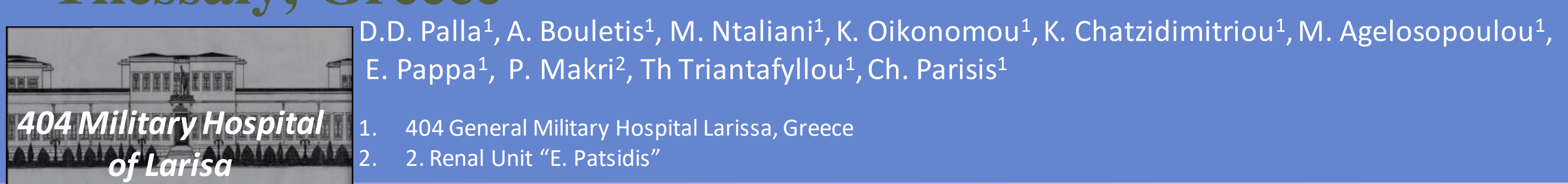

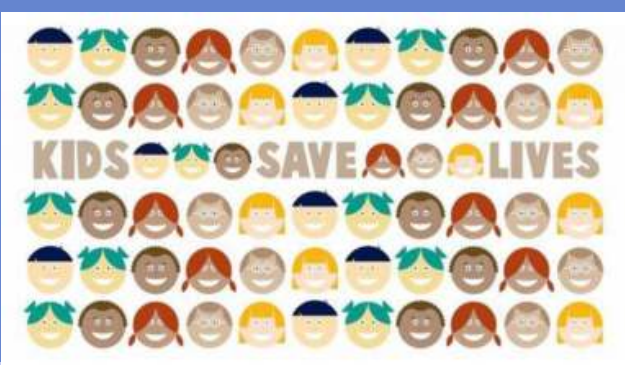

Results purpose

\title{
of this
} research was to identify potential differences in the impact of "Kids save lives" programme on students studying in schools with different curriculums (Technical

VS

omprehensive Lyceums)

Materials-Methods:

the research took place secondary schools randomly selected in the Thessaly region, Greece. 4682 students in 32 schools and participated in the "Kids Save Lives programme. We compared students studying in technical Lyceums with those in comprehensive Lyceums. Students' theoretical knowledge was evaluated before and after the programme using a questionnaire. Practical skills were evaluated with the use of manikins by experienced, ERC certified BLS instructors. Data analysis was performed with SPSS V22.

\section{Results:}

Students from technical Lyceums had poorer overall results before and after the conclusion of the programme compared to EUROPEAN

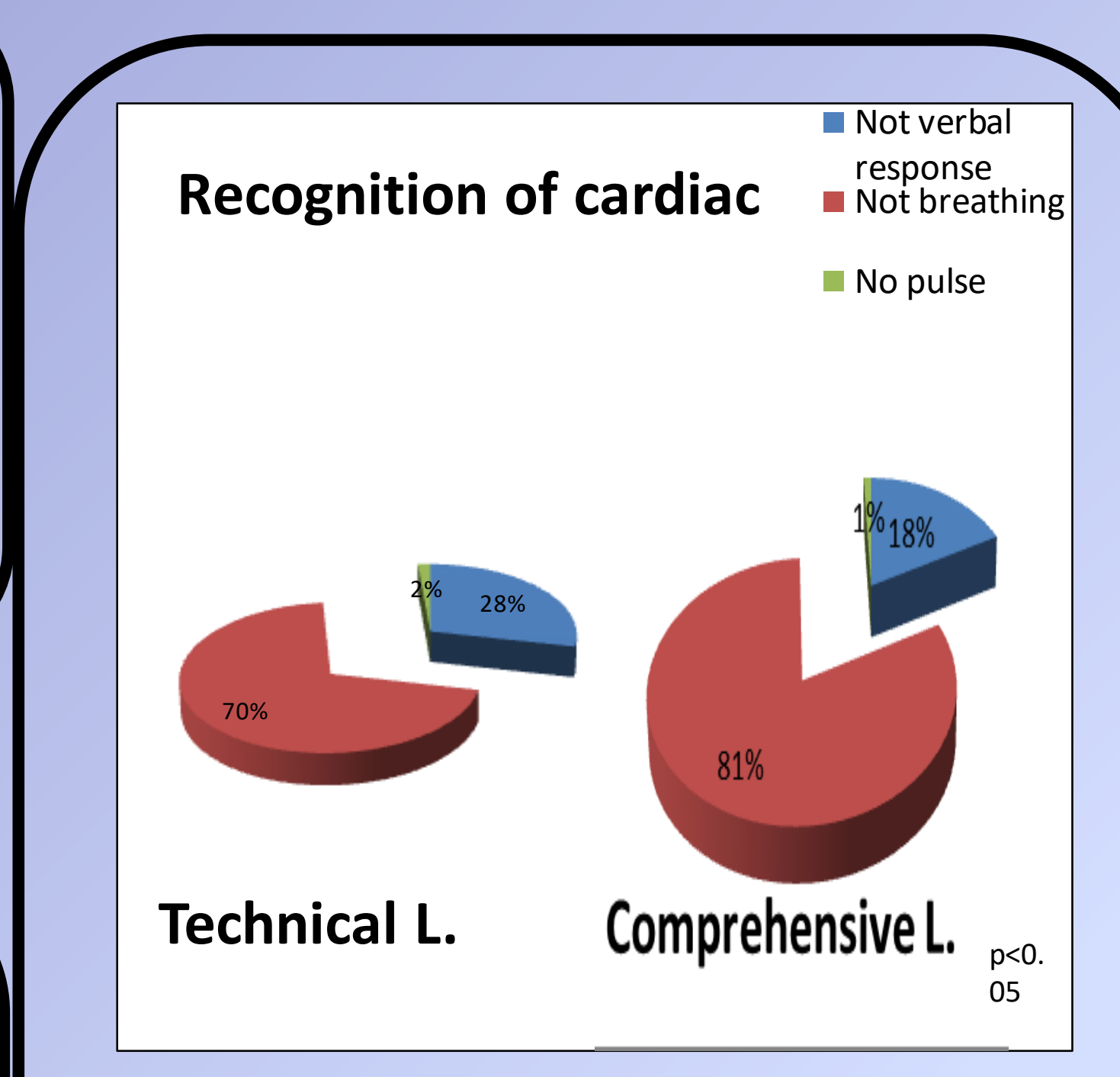

\section{Percentage of correct answers (\%)}

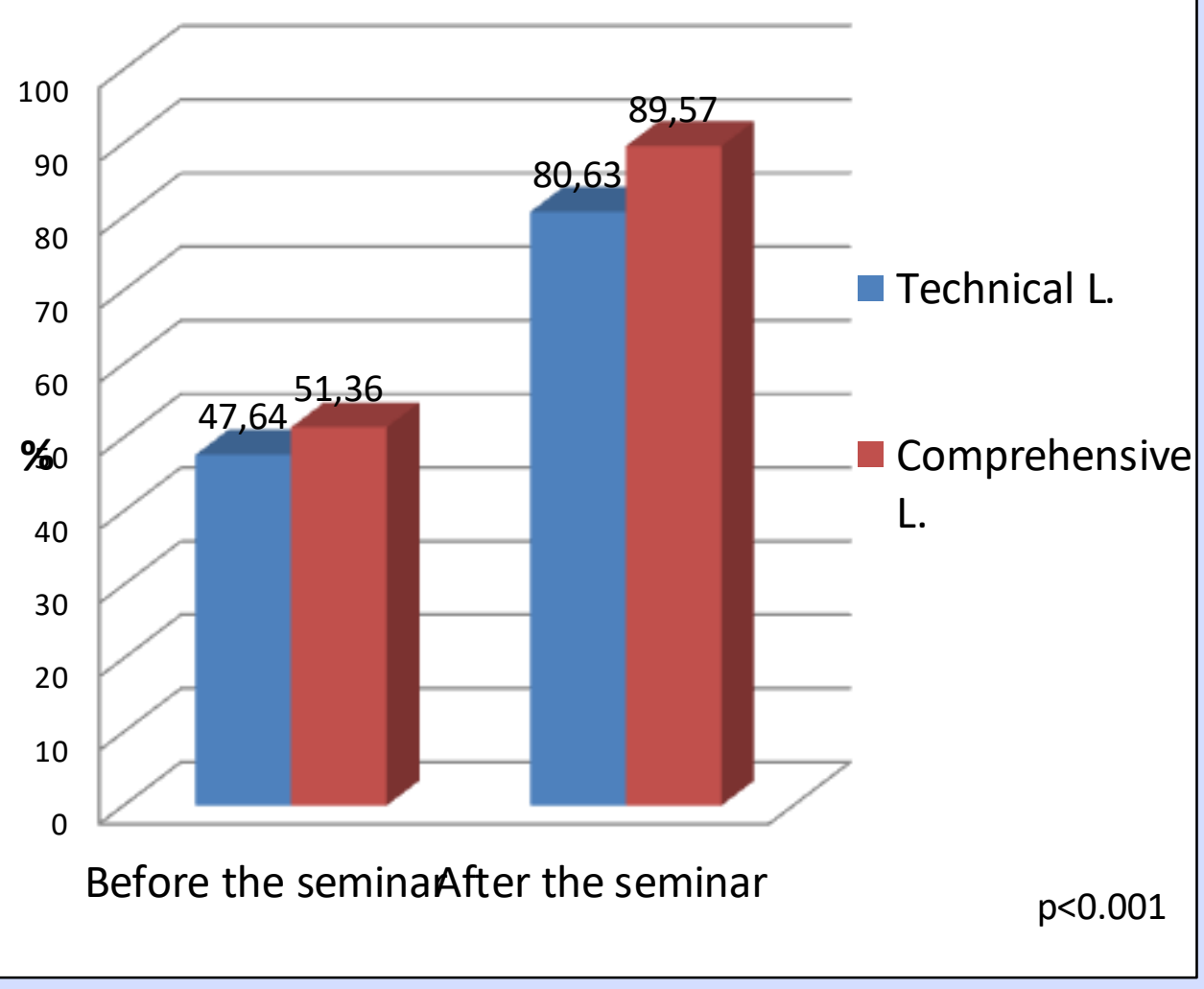

Identification of the correct BLS algorithm

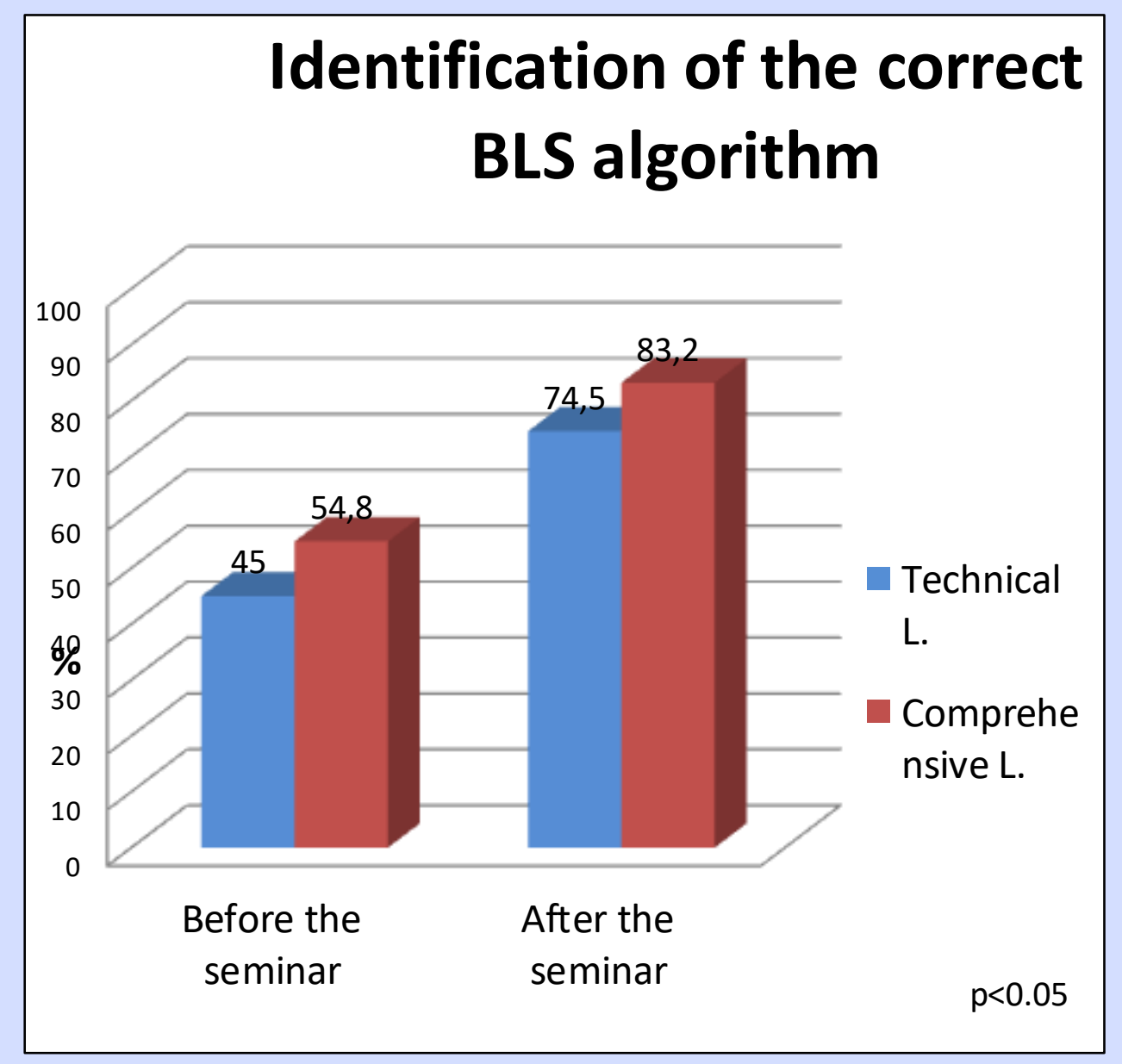

comprehensive

Lyceum students $(80.6 \%$ and $89.6 \%$ at the end, respectively). Willingness to perform cardiopulmonary resuscitation increased significantly and reached $98 \%$ on both groups after the programme. $81 \%$ of the comprehensive schools' students selected the correct cardiac arrest criteria, compared to $71 \%$ in the technical schools' students $\quad(p<0.05)$. More than $80 \%$ of comprehensive lyceum students selected the correct BLS algorithm whereas only $73 \%$ of the technical schools' students $(p<0.05)$.The difference recorded in the practical skills was not statistically significant.

Conclusions:

This study revealed a statistically significant difference in the impact of the "Kids Save Lives" programme in schools with different curriculum. Further research is needed to explore whether the repetition of the "Kids Save Lives" programme could increase its effectiveness in technicallyceums, especially regarding theoretical knowledge, or whether some different implementation of the programme may be 